\title{
Enjoyment of films as a function of narrative experience, perceived realism and transportability
}

HELENA BILANDZIC and RICK W. BUSSELLE

E-mails: helena.bilandzic@phil.uni-augsburg.de; busselle@wsu.edu

\section{Abstract}

This study investigates the relations between narrative experiences (transportation, identification, immersion and telepresence) and film enjoyment, and explores the possibility that transportability (the disposition for narrative experience) and perceived realism facilitate narrative experience and indirectly influence enjoyment. The study measured narrative experience and realism in three films from different genres. Results demonstrate that transportability, and both external realism (perceived match to the actual world) and narrative realism (perceived coherence in the story) positively influence at least one aspect of narrative experience, and that narrative experience in turn is a significant predictor for enjoyment.

Keywords: Enjoyment, film, narrative experience, realism

\section{Introduction}

Enjoyment has often been described as an essential motivator for audiences to use media and maybe even the origin of all other motives scholars have argued that enjoyment is implied in the "very idea of gratification" (Nabi and Krcmar, 2004, p. 301), the "ultimate goal" (Raney, 2004 , p. 348) and "one of the most popular gratifications sought from media" (Sherry, 2004, p. 328). As a pleasurable affective response to media use (Raney, 2003), enjoyment is one of the reasons viewers return to watch the next episode of a series, do not tune out of a film before it ends, or - over time - develop content-related viewing habits and genre preferences. Indirectly, enjoyment may be centrally important for media effects through its influence on the formation of individuals' specific content selection patterns and by inducing a particular mode of processing media content (Nabi and Krcmar, 2004). Audience members ${ }^{1}$ draw on their perceptions of media content as well as their overall view- 
ing experience to make judgments about enjoyment; both cognitive and affective reactions to media content contribute to enjoyment (Nabi and Krcmar, 2004; Raney, 2003; Raney and Bryant, 2002).

Narratives evoke cognitive and affective reactions that may be different from those evoked by rhetorical texts. This study focuses specifically on three narrative experiences that denote different yet interrelated aspects of perceiving immediacy to events, characters and emotions in a story - transportation (Green and Brock, 2002), identification (Cohen, 2002) and presence (Kim and Biocca, 1997) - and explores their influence on the enjoyment of filmic narratives. It also explores the roles of transportability - the propensity to become engaged in narratives - and perceived realism in the enjoyment of narratives. This is done from the theoretical perspective of mental models.

\section{Narrative processing and narrative experience}

A recent model of narrative engagement (Busselle and Bilandzic, 2008) embeds the narrative experience in a mental models approach. Mental models have often been used to explain how the audience makes sense of texts and filmic narratives (Wyer, 2004; Zwaan, Langston, and Graesser, 1995; Zwaan, Magliano, and Graesser, 1995). Essentially, viewers construct a dynamic situation model of the narrative, which allows for continuous monitoring of changes in time, space, protagonists, causal relations to previous events, and action structure (Johnson-Laird, 1983; Rall and Harris, 2000; van Dijk and Kintsch, 1983; Zwaan, Langston et al., 1995; Zwaan, Magliano et al., 1995). Apart from the situation model, a more stable mental structure, the story world model, is created to represent the narrated world as a coherent entity (Segal, 1995a). It indicates the setting in time-period and space, as well as a set of rules describing that which is possible in the story world, and that which is not possible, i. e., the "story world logic." For example, the story world logic of a science fiction film may allow for time travel and highly intelligent life forms that are not human beings. While this seems impossible in the real world, it is accepted by the audience as a general rule within the confines of the particular story world for the purposes of experiencing the particular narrative.

Within this framework of narrative processing, Busselle and Bilandzic (2008) locate and explain identification, transportation, presence, and perceived realism.

\section{Identification}

When building the situation model, viewers need to position themselves within the situation model, and assume "a 'here and now' point of view" 
(Rall and Harris, 2000, p. 202). This perspective helps them interpret the narrative in two ways. First, contextual words like "here", "we" or "now" can only be understood from the position of the speaker and the context of the situation (Segal, 1995b). Second, motives, emotions and narrative evaluations of events depend on a specific perspective and can often be understood only if the viewer sees the narrative world from a character's viewpoint. This process has been described outside the mental models literature as identification or perspective taking (Cohen, 2001). Identification is the process by which we can simulate in our minds what we read or view. Audience members adopt characters' goals and experience the emotions that are implied from a character's perspective (Oatley, 1994). Thus, audiences understand and react to events, successes or misfortunes in a way that mirrors real world experience. In this sense, a fictional simulation takes place in which a perceiver (reader, listener or viewer) may experience narrative events in his or her own emotional and cognitive processing systems, very much like a guided dream or a computer simulation (Oatley, 1994, 1999; Oatley and Gholamain, 1997).

The phenomenon of adopting a point of view with a story is emphasized by many descriptions of narrative processing (Cohen, 2001; Gernsbacher, Goldsmith, and Robertson, 1992; Laszlo and Cupchik, 1995; Oatley, 1994, 1999), and is what separates narrative experiences from other immersive experiences, such as chess or sport.

\section{Transportation}

Green, Brock and Kaufman (2004) link the natural tendency of individuals for perspective-taking to the phenomenon of transportation. In transportation, audience members focus on the narrative, and react cognitively and emotionally to it, losing awareness of the actual world around them (Green and Brock, 2000, 2002). Transportation is often compared to the concept of flow (Csikszentmihalyi, 1991). Both involve full attention to an activity, tuning out the actual world, and ignoring time's passage. A mental models perspective specifies that attention is focused on constructing mental models in order to comprehend the narrative. If this process goes smoothly and people do not think about their actual world and their own identity, they perceive flow, which may be measured as transportation into the narrative (Busselle and Bilandzic, 2008).

Transportation denotes a transgression from the actual to a fictional world that is similar to identification. To distinguish between the two concepts, mental models again may be useful. Identification describes 
assuming a point of view of a character or characters within the story, while transportation denotes the holistic experience of perceiving flow while constructing the mental models of the story.

\section{Telepresence}

Both transportation and identification assume that viewers shift their center of perception and thinking away from the actual world and into the narrative world. A similar phenomenon, telepresence, has emerged from virtual reality research (Biocca, 2002; Bracken, 2005; Lombard and Ditton, 1997) and was defined as the "perceptual illusion of non-mediation" (Lombard, Reich, Grabe, Bracken, and Ditton, 2000, p. 77). Users focus mentally on the content that is mediated and on their own behavioral options, no longer perceiving the medium (Wirth et al., 2007). In contrast to computer-mediated non-narrative environments that are often used as stimuli in telepresence research, in narrative processing the sense of "being there" is not created by sensory stimulation, but by assuming the perspective of a character and making sense of the narrative's events and emotional structure. Thus, the outcome of narratives and computer-mediated environments may be similar (changing perceptual frames) but the causes are different. Nonetheless the sense of being there is often described for narratives and seems to be an important phenomenon in narrative experience (Gerrig, 1993; Green and Brock, 2000). Lombard and Ditton (1997) even specify transportation as one of six conceptualizations of telepresence. Within the mental models approach, telepresence results from the shift of the viewer's perspective into the mental model. This shift temporarily focuses attention on perceiving the fictional world, while the actual world fades from conscious awareness.

While each of the three phenomena are conceptualized differently and thought to originate from different processes, they share three things: Each implies that audience members 1) devote full or near full attention to the media stimulus, 2) perceive the stimulus from a point of view situated within the mediated world, and 3) lose awareness of the actual world around them. In the cases of transportation and identification, audience members also lose awareness of themselves. In the case of telepresence in a non-narrative virtual world, one may focus attention on one's apparent presence in the artificial environment.

\section{Perceived realism}

Each of these sensations may be threatened by factors that may draw attention away from the narrative world, for example, noise in the envi- 
ronment or hunger. Other distracting factors may originate from the narrative itself. These distractions may come in two forms. Violations of external realism occur when the narrative is inconsistent with actual world experiences or expectations. Violations of narrative realism occur when the story itself is internally inconsistent, for example when a character's behavior is inconsistent with her motivations or goals (Busselle and Bilandzic, 2008; see also narrative probability, Fisher, 1987; narrative consistency, Hall, 2003).

Narrative experiences such as transportation, identification and telepresence suffer when attention is drawn away from processing the narrative from an inside point of view to thinking about the narrative as an artificial construct from a perspective outside of the narrative. Thus, violations of both types of realism should undermine or reduce the intensity of narrative experience.

Certainly not all violations of external realism evoke spontaneous protests - otherwise whole genres like science fiction or fantasy would not be as successful as they are. Some divergences from the actual world are explained by the story world logic - the presence of sorcerers and witches in the Harry Potter series is explained by a story world logic that allows magic. Only divergences that are not explained by the story world logic should prompt critical thoughts and should disturb the narrative experience. From a mental models perspective, inconsistencies within a story result in clashes between mental models constructed up to a certain point with new, incoming narrative information, resulting in interference in the smoothness of the process and a less intense narrative experience (Busselle and Bilandzic, 2008).

\section{Escape and enjoyment}

Escape is often connected to immersive media use and thought to be responsible for media enjoyment. For example, Sherry (2004) argues that enjoyment of escapist media results from intense focus on content and loss of self-consciousness. Green, Brock, and Kaufman (2004) characterize transportation as a desired state that provides an escape from the everyday world. Conceptualizations of narrative experience and escape share a set of metaphors that express leaving the actual world and entering a possible world. Escape through narratives may be separated into two analytically different, but closely related phenomena: (1) viewers psychologically lose awareness of their actual world and detach themselves from their own existence, and (2) they enter a fictional world where they assume other people's selves and experience alternative complications and events. 
(1) Leaving the actual world. Leaving the actual world suggests the classical functional perspective of escape and may be achieved through any mediated or non-mediated, narrative or non-narrative activity that provides flow. In the case of mediated experiences the viewer is relieved from the self and from the negative concerns of the actual world (Henning and Vorderer, 2001; Katz and Foulkes, 1962). Narrative experiences, like other flow activities, create a diversion from one's own problems (Green et al., 2004). One may feel temporary relief from imminent decisions, negative events, and existential fears. Also, viewers may cease to think about the impression they make on other people and indulge in emotional reactions that are quite contrary to what is typical for them (Sherry, 2004). Similarly, immersion in narratives may also provide disengagement from the moral rules of the actual world (Raney, 2004).

Each of the processes mentioned here may also result from activities other than immersing oneself in a narrative - for example, exercising or housecleaning. However, narratives provide an additional value for those who want to escape, and this value may be explained by looking at what happens when viewers enter a narrative world.

(2) Entering a narrative world. As we have elaborated above, we assume that viewers need to move into the narrative, which first and foremost means that they need to take on the perspective of a character. Thus, viewers are given the opportunity temporarily to be a different person. Green, Brock and Kaufman (2004) state that transportation may provide the opportunity for identity play, for trying out "possible selves" (p. 318), without having to actually change one's life or having costs other than time. They argue that such self-expansion is related to the positive affect that may result in enjoyment.

Indeed, trying out "possible selves" should be an effective way of temporarily detaching oneself from one's own identity. This can be explained through the process of identification. As we argued earlier, identification, in other words, assuming the point of view of a character is a prerequisite for understanding the narrative and for transportation. Oatley and Gholamain (1997) argue that escape can be thought of as "taking a ride on a character's goals and plans, just as we take a ride on a rollercoaster" (p. 277). Not only does identification distract from one's own identity. It does so by temporarily substituting one's own perspective with another person's perspective on events, people, and emotions in that other world. From a cognitive capacity standpoint, thinking about a character's problems will leave little capacity for thinking about one's own problems. For this reason, narratives may be particularly effective for escape - more effective than other immersive activities. 


\section{Specifics of the Narrative Experience}

Two specifics of narrative experience may directly contribute to an audience member's perception of enjoyment, regardless of escape: Experiencing extraordinary events and transforming oneself (Green et al., 2004).

\section{Experiencing Extraordinary Events}

Narratives make the audience experience events and emotions that are otherwise not accessible in actual life. Viewers are confronted with extraordinary events and conflicts that the film's characters eventually must resolve. Intense emotions, matters of life and death, of sense and senselessness, are at the very heart of every story that is worth telling and separate the fictional world from the everyday life of the actual world (Abbott, 2002; Prince, 1982). As Tan (1996) points out, in film we find "condensed or exaggerated versions of reality" (p. 51) with an "unusually high concentration of emotional stimuli" (p. 50). Being part of such exceptional events and emotions makes films memorable and outstanding relative to everyday life. Oatley and Johnson-Laird (1996) see emotional experience as one reason people like to immerse themselves in fiction: emotional states are generally liked and looked for, and fiction provides an opportunity to engage in these emotional states. For this process the valence of the emotions need not be positive (Green, Brock, and Kaufman, 2004). Negative emotions serve the same function of giving the audience the opportunity to be part of something extraordinary. This is reflected in research on tragedy, drama, and horror fiction that found that negative emotions such as sadness or fear also lead to enjoyment (Oliver, 1993). Narratives provide a safe space for an experience that may be dangerous or life-threatening in real life (Nell, 1988).

\section{Transforming Oneself}

A narrative may transform perceivers by giving them insights into their own lives, selves or into general truths of life (Green et al., 2004). It may instigate reflection about the appropriateness of moral rules, norms and values. Moreover, a character's fate may prompt reflection about one's own fate, in terms of coping, action options and possible outcomes, but also on a more general level when a comparison with a character's fate makes one's own problems seem less serious.

Each of the mechanisms through which narratives may provide enjoyment should depend on the intensity of the narrative experience. Thus, we predict that intensity of transportation, identification and telepresence increases enjoyment of films (H1) and perceived realism (narrative and external) facilitates narrative experience (H2). 


\section{Disposition for narrative experience: Transportability}

If enjoyment depends on one's reactions to the narrative and to the viewing experience as a whole, we may assume that certain traits exist that predispose the viewer to react and consequently to enjoy narratives. While transportation is generally conceptualized as a situational phenomenon, it is plausible that there is a situation-independent individual tendency to be transported. A measure for such a personality trait, called transportability, was developed and tested by Dal Cin, Zanna, and Fong (2004). Transportability indicates self-reported frequency of transportation and ease of experiencing transportation. In their study, Dal Cin et al. (2004) found that transportability does indeed correlate with situational transportation. We hypothesize that transportability increases narrative experience $(\mathrm{H} 3)$.

\section{Study}

\section{Design and participants}

The study consisted of four parts. The first questionnaire collected data on general preferences in viewing and reading narrative, followed by three quasi-experiments one week later during which participants were shown three different movies. The first questionnaire was distributed in introductory communication classes where participants were also recruited for the experiment. Students were given extra credit for participating in all parts of the study.

In the experiments, participants watched a feature film in a university auditorium on three consecutive nights and answered questions about their viewing experience afterwards. The first questionnaire was completed by 250 undergraduates. Of these, 162 participants completed all four parts of the study. Participants' ages ranged from 18 to $56(M=$ 21.35; $S D=3.67)$. Fifty-five percent were female.

\section{Stimulus material}

Three films were chosen as stimuli for narrative experience, each from a different genre to provide variation in liking among the participants. The genres crime thriller, romantic comedy and science fiction were chosen as they represent a wide range of popular and successful genres. In choosing the individual films, we tried to find examples that were unknown to an audience of young adults, yet not as aged that differences in the contemporary style of feature films were apparent. We chose Gattaca (directed by Andrew Niccol, 1998; science fiction), A Murder of Crows (directed by Rowdy Harrington, 1998; crime thriller), and The Very 
Thought of You (directed by Nick Hamm, 1998; romantic comedy). In contrast to Dal Cin, Zanna, and Fong (2004), we used complete motion pictures as stimuli. Using short versions of films may reduce the overall plausibility and appeal of the films.

The questionnaire completed after the movies contained a question asking whether the movie had been watched before. However, there were no significant differences between participants who indicated that they had seen the movie and those who had not seen it on any dimension of narrative experience. Therefore, all participants were retained in the sample.

\section{Measures}

The transportability scale was taken from Dal Cin, Zanna, and Fong (2004), who adapted the transportation scale used by Green and Brock (2000) to fit a trait (20 items, Cronbach's $a=.88$ ).

In the questionnaires that were administered after each exposure, enjoyment was measured using an adapted attribute list from Perry, Jenzowsky, Hester, King, and Yi (1997), which consisted of 14 attributes (exciting, suspenseful, interesting, entertaining, good, likeable, funny, humorous, imaginative, dull (reversed), amusing, depressing (reversed), well made, stereotypical (reversed)) and had good reliabilities in each film (crime $a=.85$; science fiction $\alpha=.87$, and romantic comedy $a=.92)$.

External realism was measured using a scale that was adapted to narrative by Green (2004) from a subscale of the perceived reality scale by Elliot, Rudd, and Good (1983). This subscale contains 8 items that relate to a comparison between the fictional and the actual world. We removed one item ("This story shows that people have both good and bad sides") that lowered reliability in two films and did not improve it in the third film. In all three films, reliability was good (crime thriller $a=.80$; romantic comedy $a=.74$; science fiction $a=.74$ ).

A scale for narrative realism was developed for this study. A set of items covered two dimensions relevant for narrative realism, logical coherence (extent to which the narrative is perceived as flawless and consistent), and emotional/motivational plausibility (viewers are able to understand the actions and feelings of the characters). Items were analyzed as to their coherence and some were removed to improve reliability. A final solution with five items (The story was logical and convincing; It was understandable why the events unfolded as they did; It was understandable why the characters behaved the way they did; The actions and reactions of the characters were plausible; The actions and reactions of the characters were in tune with their personalities) loaded on one dimension 
in a factor analysis, and produced good reliabilities (crime thriller $\alpha=.83$; romantic comedy $a=.83$; science fiction $\alpha=.80$ ).

Transportation was adapted for film from Green and Brock (2000). The terms "reading" or "narrative" were replaced with "watching" and "film." In order to produce comparable measures for each film, the items that were formulated with specific character names were reduced to one general judgment about experiencing the characters in the films (e.g., instead of the item "While watching the film, I had a vivid image of Vincent" we used "While watching the film, I had a vivid image of the characters"). For identification, we used the items that were proposed by Cohen (2001). Again, the term "program" was replaced by "film", and instead of detailing each character's name, we used an abstract statement about the characters in general. Telepresence was measured with the 8 -item scale by Kim and Biocca (1997), again, replacing words like "broadcast" or "television" with "movie".

While each of the narrative experience scales had good reliabilities, the correlations of the three scales with each other were quite high (well above $r=.5$ ). This is partly due to conceptual overlap, but partly also due to the use of similar items. For example, the identification scale contains items for absorption that are close to some transportation items. To avoid problems of multicollinearity, we reduced the three narrative experience scales to items that represent the core concept of each scale. Three exploratory factor analyses were run, one for each film in a principle axis factoring with Promax rotation. The criteria to retain items were: that (1) several items of the same scale loaded on the same factor in at least two films with primary loadings of at least .4, and (2) no double loadings of more than half of the primary loading were present in at least two films.

Similar patterns emerged for all three films. Identification and telepresence loaded on two separate factors with a reduced set of items that cohere well when combined in a scale (items for telepresence: The movie came to me and created a new world for me, and the world suddenly disappeared when the movie ended; During the movie, I felt I was in the world the television created; When the movie ended, I felt like I came back to the 'real world' after a journey; During the movie, my body was in the room, but my mind was inside the world created by the movie; During the movie, the movie-generated world was more real or present for me than the 'real world.' Cronbach's $a$ for short telepresence scale: crime thriller: .89; romantic comedy: .86; science fiction: .86. Items for identification: While viewing the show I could feel the emotions of the characters portrayed; I tend to understand the reasons why the characters do what they do; I think I have a good understanding of the characters; I was able to understand the events in the program in a manner 
similar to that in which the characters understood them. Cronbach's $a$ for short identification scale: crime thriller: .84; romantic comedy: .84; science fiction: .86.) Transportation separated into three factors for all three films. One factor denotes overall involvement in the story plot (items: I wanted to learn how the story ended; The story affected me emotionally; I found myself thinking of ways the story could have turned out differently; I was mentally involved in the story while watching the movie. These items were combined into a short transportation scale with Cronbach's $a$ for crime thriller: .67; romantic comedy: .71; science fiction: .73). The second factor coming out of transportation expresses immersion into the film (Items: After finishing the movie, I found it easy to put it out of my mind (reversed); I found my mind wandering while watching the movie (reversed); While I was watching the movie, activity going on in the room around me was on my mind (reversed). Cronbach's $a$ for immersion scale: crime thriller: .63; romantic comedy: .71; science fiction: .69). The third factor is relevance for the viewer's life and is composed of two items (The events in the story have changed my life; the events in the story are relevant to my everyday life) that correlate highly (crime thriller: $r=.59$; romantic comedy: $r=.60$; science fiction: $r=.52$ ). Although the two new factors immersion and relevance were not conceptually accounted for by the theory, we will retain them as they usually feed into the transportation scale.

\section{Results}

The hypotheses were tested with path models for each of the film data sets using AMOS 7. 0. Path analysis was chosen over multiple regression because it can take correlations between the independent variables into account: The reduced scales of narrative experience are still correlated with each other at moderate levels (see Tables 1, 2 and 3); even if these correlations are not as high as between the original scales and do not cause serious multicollinearity problems in regressions, a method is preferable that explicitly accounts for such relationships. In addition, path analysis allows for testing indirect effects of independent variables rather than only testing additive effects of the independent variables. This is particularly important for transportability and realism - both should contribute to enjoyment indirectly through the narrative experiences rather than directly influencing enjoyment.

The sample size of $n=162$ is at the lower tolerable limit for path analysis. However, the scales that served as input for the analysis were thoroughly checked for deviations from normality, and only variables that conformed to a normality assumption were used. There were no missing values and no outliers. The only scale that had to be eliminated 


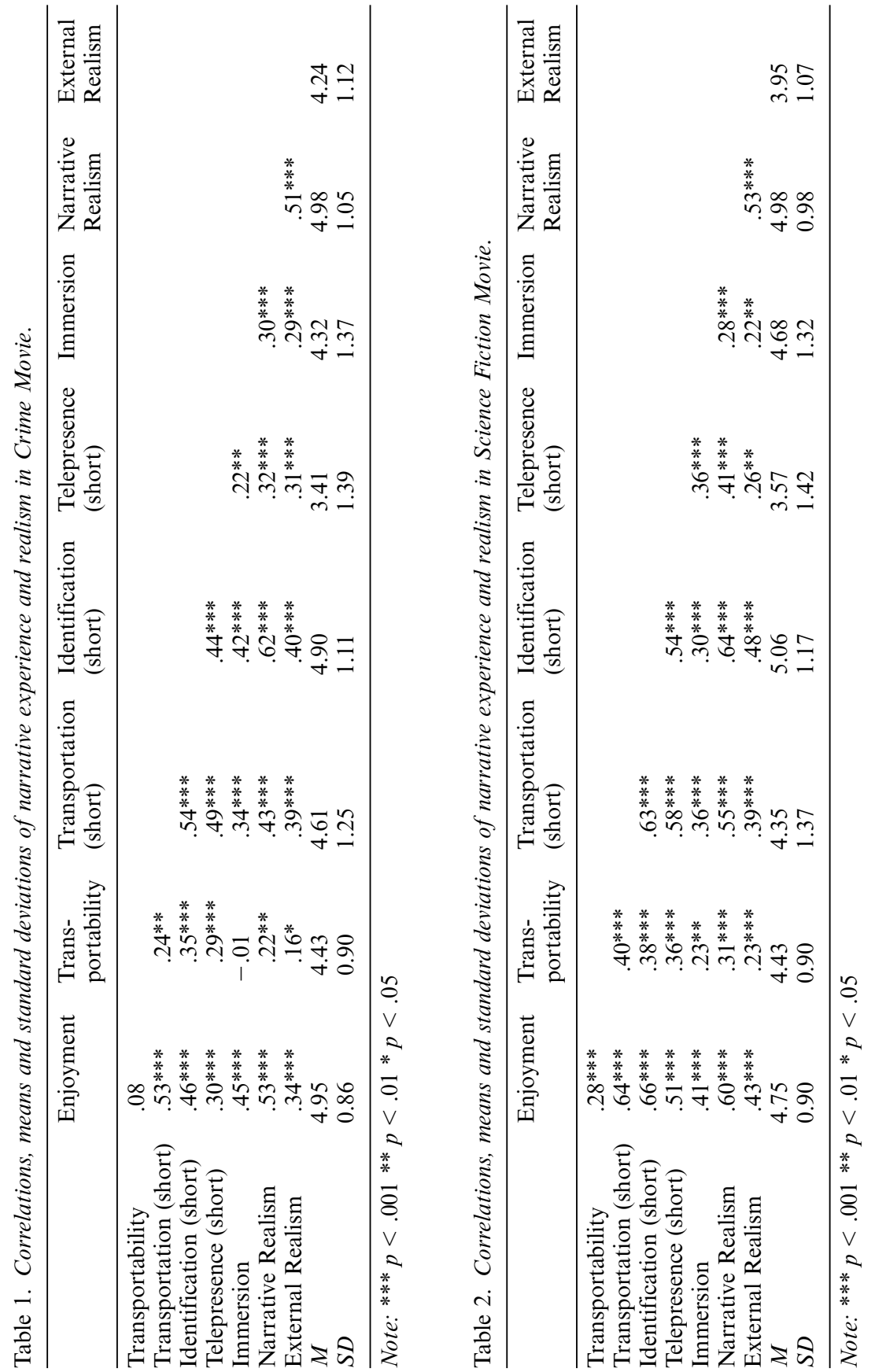




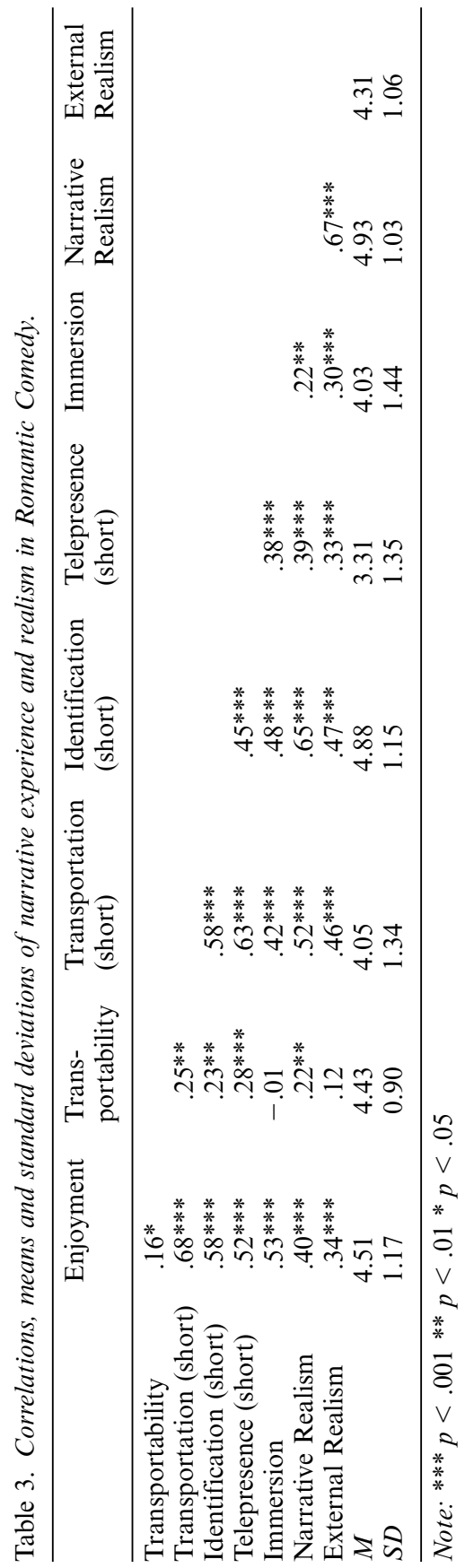




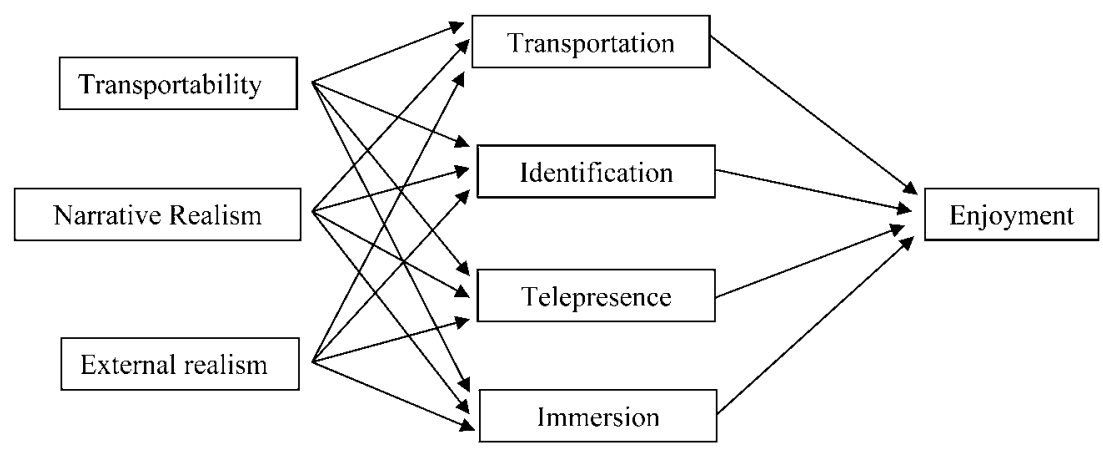

Figure 1. Theoretical model for path analysis.

due to deviations from normality was relevance: it turned out to be skewed for all three film data sets $(>1.0)$ and kurtotic in two cases $(>1.5)$. All other scales were within normal range $(< \pm 1.0)$, except for one instance in which narrative realism's kurtosis was at 1.25 , which we judged acceptable considering its normality in all other cases. The small sample size, however, and also the small number of variables in some of the scales were reasons not to apply structural equation models with original variables as indicators. The original variables are much more prone to deviate from normality than variables combined into scales at such small sample sizes. The sample size, however, was a trade-off between being able to perform adequate statistical analyses and having panel data that allow the explanatory power of transportability to be tested over several instances of narrative exposure and across different genres.

The theoretical model that was our starting point specified that transportability and both types of realism would predict each of the narrative experience variables (short transportation, short identification, short telepresence, immersion). Then the narrative experience variables would predict enjoyment (see Figure 1).

The path models were developed by first eliminating all insignificant variables and paths from the equations and then by adding co-variances between error terms as suggested by modification indices. No latent variables were included to represent narrative experience or realism as a unitary construct, because we were interested in the different contributions of the narrative experience dimensions.

In all three models, which represented the three films and are illustrated in Figures 2, 3 and 4, the path coefficients from telepresence to enjoyment were not significant. Therefore, telepresence was eliminated from further analyses. Common patterns of relations emerged across the 


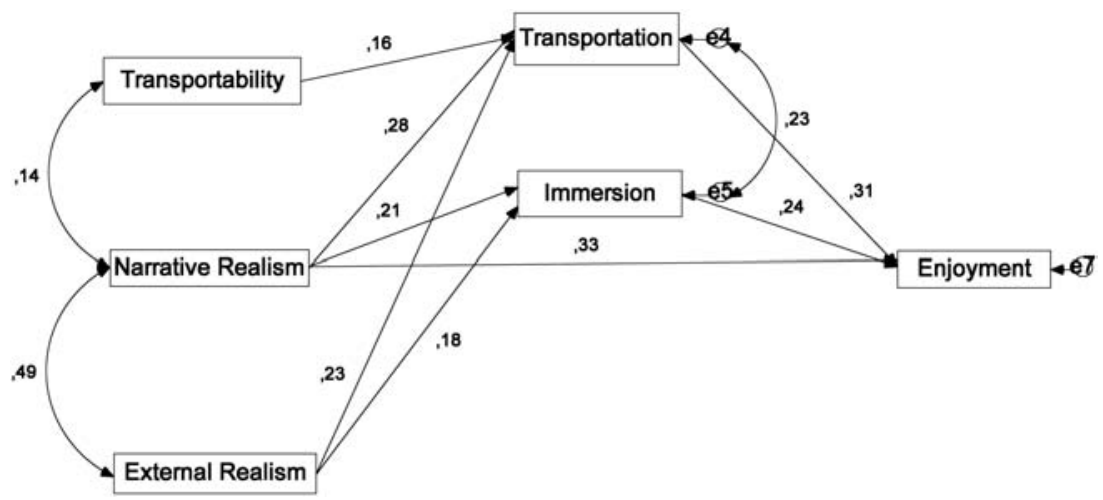

Figure 2. Path analysis for crime thriller.

three models. In each case transportation into the film was predicted by transportability (crime-thriller $\beta=.16$, romantic comedy $\beta=.13$, scifiction $\beta=.24$ ) and narrative realism (crime-thriller $\beta=.28$, romantic comedy $\beta=.48$, sci-fiction $\beta=.48$ ). Also, in each model enjoyment was predicted by transportation (crime-thriller $\beta=.31$, romantic comedy $\beta=.46$, sci-fiction $\beta=.29$ ) and immersion. The models differed from each other in some details. Each model is described more specifically below.

In the model representing the crime-thriller film, direct contributors to enjoyment were transportation $(\beta=.31, p<.001)$, immersion $(\beta=.24$, $p<.001)$, and narrative realism $(\beta=.33, p<.001)$, with approximately equal strengths. Narrative realism $(\beta=.28, p<.001)$ and external realism $(\beta=.23, p<.001)$ both explain transportation. Narrative realism $(\beta=.21, p<.001)$ and external realism $(\beta=.18, p<.001)$ also explain immersion. The model was improved when narrative realism was allowed to correlate with transportability and external realism; as well as the errors of transportation and identification. In summary, the model suggests that transportability as a general predisposition predicts transportation into the specific film, which in turn influences enjoyment of the film. Also, both narrative realism and external realism influence enjoyment through transportation and immersion. Finally, narrative realism also appears to have a direct influence on enjoyment. The final model (see Figure 2) fit the data, as indicated by several model fit indices $\left(x^{2} / d f=1.60 ;\right.$ CFI $=.99 ;$ RMSEA $=.06$, CI low $=.00$, high $\left.=.14\right)$.

In the romantic comedy model, three narrative experience variables, transportation $(\beta=.46, p<.001)$, immersion $(\beta=.24, p<.001)$ and identification $(\beta=.20, p<.001)$, each predicted enjoyment, with trans- 


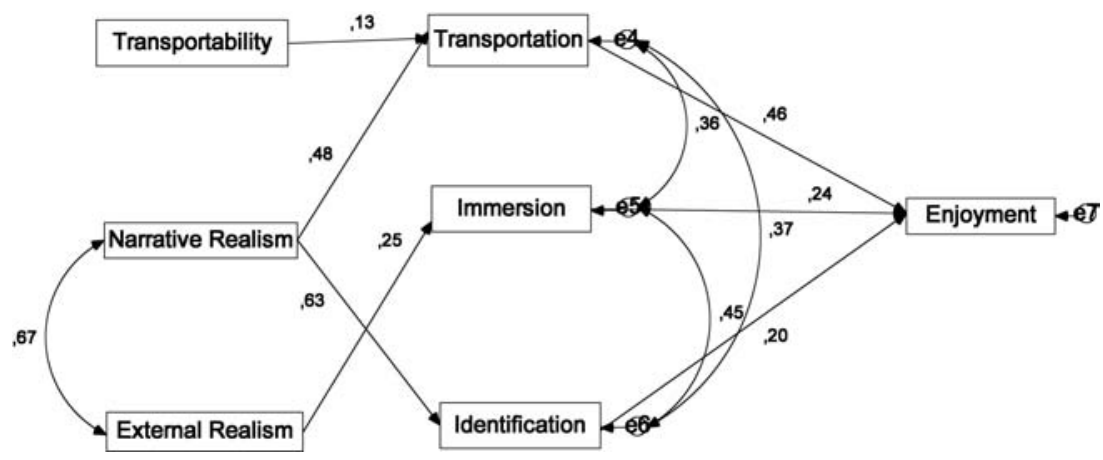

Figure 3. Path analysis for romantic comedy.

portation being the strongest. Again, transportation was predicted by transportability $(\beta=.13, p<.05)$ and narrative realism $(\beta=.48$, $p<.001)$. Narrative realism also predicted identification $(\beta=.63$, $p<.001)$. External realism predicted immersion $(\beta=.25, p<.001)$. The model was improved when errors of all narrative experience variables and errors of the two realism variables were allowed to co-vary (see Figure 3). In summary the model suggests that transportability predicts transportation, which influences enjoyment. Narrative realism influences enjoyment indirectly through transportation and identification. Also, external realism influences enjoyment through immersion. The model fit was good on all indices except RMSEA that generally tends to overreject models run on small sample sizes $\left(x^{2} / d f=1.99\right.$; CFI $=.98$; RMSEA $=.08$, CI low $=.02$, high $=.13$ ).

In the model for science fiction, enjoyment was predicted by transportation $(\beta=.29, p<.001)$, immersion $(\beta=.17, p<.001)$ and identification $(\beta=.30, p<.001)$, as well as by a direct path from narrative realism $(\beta=.21, p<.001)$. Transportation was predicted by transportability $(\beta=.24, p<.001)$ and narrative realism $(\beta=.48, p<.001)$. Immersion was predicted by narrative realism $(\beta=.28, p<.001)$. Identification was predicted by transportability $(\beta=.19, p<.001)$, narrative realism $(\beta=.51, p<.001)$ and external realism $(\beta=.14, p<.05)$. The error terms of transportation were related to errors of both immersion and identification, as were both realism types. In addition, transportability was related to external and narrative realism. In summary, transportability predicts transportation, which influences enjoyment. Transportability also predicts identification, which also influences enjoyment. External realism predicts identification, which influences enjoyment. Finally, narrative realism influences enjoyment directly, as well as indi- 


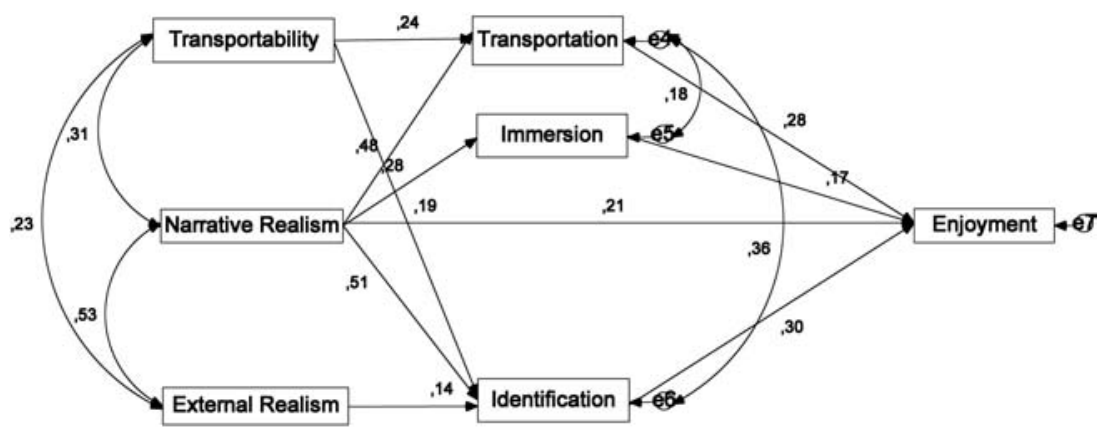

Figure 4. Path analysis for science fiction movie.

rectly through transportation, immersion and identification. This model (see Figure 4) fit the data well $\left(x^{2} / d f=1.83 ; \mathrm{CFI}=.99\right.$; RMSEA $=.07$, CI low $=.00$, high $=.14$ ).

\section{Discussion}

The goal of the study was to assess relationships between narrative experience (transportation, identification, telepresence), transportability (the disposition for narrative experience), perceived realism, and enjoyment. Three films from different genres (crime thriller, romantic comedy and science fiction) were used as stimuli to provide narrative experiences in the same respondents. Transportability was measured at least one week prior to exposure. Owing to conceptual and statistical overlap among the original narrative experience scales, we reduced the scales in exploratory factor analyses to core items that loaded on different factors. The factor structure that emerged from all three data sets was used for analysis. The transportation scale was split into three parts in this procedure, a core transportation component, one that was called immersion (concentration on the film) and one that was called relevance (relation of the film to one's own life). However, the new relevance factor was dropped in the subsequent analysis because it did not conform to the normality distribution.

Our assumptions were that the narrative experience of transportation, identification, telepresence and the new immersion factor would increase enjoyment of a film. We hypothesized that external realism (perceived match to the actual world) and narrative realism (perception of coherence in the story) positively influence narrative experiences and thus indirectly contribute to enjoyment. The same indirect effect through narrative experience was assumed for transportability. 
Path analyses of all three film data sets demonstrated that transportation and immersion positively contributed to enjoyment. Identification influenced enjoyment in two of the three films. Both types of perceived realism influenced enjoyment indirectly via the narrative experience variables. Through which narrative experience variables the realism types were effective, differed from film to film. In one case, the contribution of external realism operated through immersion, in another through identification and in the third one through immersion and transportation. Narrative realism was effective through transportation and identification in one case, through transportation, identification and immersion in the second and transportation and immersion in the third case. In two of the three films, narrative realism also contributed to enjoyment directly. In all three films, transportability predicted transportation, in one case, it also predicted identification. There were no direct influences of transportability or external realism on enjoyment in any of the films.

Transportation, immersion and identification were the prevalent aspects of narrative experience that connected to enjoyment; transportability, narrative and external realism always predicted some aspect of narrative experience. It is striking however that the aspect of narrative experience that was predicted by transportability and realism varied across the three data sets. This may be indicative of methodical issues in this study or of differences in the stimulus films. For example, unlike the other two films, the crime film was based more on plot than characters, which may explain the irrelevance of identification in that model. The scales for narrative experience were taken from existing instruments and modified to be distinct from each other statistically. Each of the resulting scales represents a facet of narrative experience, but is not attuned to each other theoretically or methodically. For example, the short transportation scale seems to be much more general and comprehensive than telepresence, identification or immersion. It is conceivable that the more general scales were stronger in the path analysis not because of the concept they represent, but because they cover a more heterogeneous and comprehensive facet of narrative experience. Future research should address this and develop measures that cover all aspects of narrative experience at a similar level of abstraction and depth rather than relying on instruments that have been developed separately and for different reasons.

A second limitation of this study is that the data analytic procedure employed was exploratory rather than confirmatory. There were several reasons for this. First, the theoretical model used as original input was modified in several cycles based on criteria the data themselves provided, that is, significance of parameters and modification indices, to improve model fit. Usually, a confirmatory run of the final model on a separate 
portion of the sample is in order to demonstrate lack of over-fitting. The small sample size however prohibited that procedure. While there is evidence that transportability and realism support narrative experience, the pattern does not represent a proper replication and confirmation of the structure. This is because the two endogenous constructs predict different narrative experience variables in different films. Second, the small sample size and the characteristics of the scales used may have brought instability and idiosyncrasies into the analyses. Thus, the present analysis should be regarded as heuristic for generating more specific hypotheses to be tested with improved instruments.

The question of whether narrative experience influences the audience's judgment of enjoyment is relevant for two reasons. First, it adds to our understanding of how content preferences are developed and what experiences audiences seek, appreciate or need when they turn to media stories. This may inform our knowledge about media motives and functions, and help define unspecific motives such as pastime, distraction or entertainment. Second, while narrative experience adds to enjoyment, it also modifies media outcomes. Transportation, for example, is thought to reduce counter-arguing and increase elaboration of a narrative's assertions, resulting in increased persuasion (Green and Brock, 2000). This means that people are influenced most by the stories they like most. This is important for investigating effects in a naturalistic setting - when viewers make their own decisions about what to watch, and make these choices over long periods of time, as implied by cultivation research. Narrative experiences are enjoyed, and should motivate viewers to watch other films of the same genre or the next episode of a series. Narrative experience also increases the probability of persuasive effects. Thus, selfselection induces a process in which motivation and effects are intertwined, and driven by the same process: narrative experience.

\section{Bionotes}

Helena Bilandzic is Professor at the Department for Media and Educational Technology, Augsburg University, Germany.

Rick W. Busselle is Associate Professor at the Murrow College of Communication, Washington State University, United States of America.

\section{Note}

1. While this study is primarily concerned with film viewing, we use the term "audience members" to refer to all consumers of narratives; those reading a novel, watching television or film, or listening to an audio play. 


\section{References}

Abbott, H. P. (2002). The Cambridge introduction to narrative. Cambridge: University Press.

Biocca, F. (2002). The evolution of interactive media. Toward being there in nonlinear narrative worlds. In M. Green, J. Strange \& T. Brock (Eds.), Narrative Impact. Social and cognitive foundations (pp. 97-130). Mahwah, NJ: Lawrence Erlbaum.

Bracken, C. C. (2005). Presence and image quality: The case of high-definition television. Media Psychology, 7, 191-205.

Busselle, R. W. \& Bilandzic, H. (2008). Fictionality and perceived realism in experiencing stories: A model of narrative comprehension and engagement. Communication Theory, 18, 255-280.

Cohen, J. (2001). Defining identification: a theoretical look at the identification of audiences with media characters. Mass Communication and Society, 4(3), 245264.

Csikszentmihalyi, M. (1991). Flow: The psychology of optimal experience. New York: Harper.

Dal Cin, S., Zanna, M. P., \& Fong, G. T. (2004). Narrative persuasion and overcoming resistance. In E. S. Knowles \& J. A. Linn (Eds.), Resistance and persuasion (pp. 175-191). Mawah, NJ: Erlbaum.

Elliot, W. R., Rudd, R., \& Good, L. (1983). Measuring the perceived reality of television: perceived plausibility, perceived superficiality and the degree of personal utility. Paper presented at the Annual Meeting of the Association for Education in Journalism and Mass Communication, Corvallis, OR.

Fisher, W. R. (1987). Human communication as narration. Toward a philosophy of reason, value and action. Columbia, SC: University of South Carolina Press.

Gernsbacher, M. A., Goldsmith, H. H., \& Robertson, R. R. W. (1992). Do readers mentally represent characters' emotional states? Cognition and Emotion, 6, 89111.

Gerrig, R. J. (1993). Experiencing narrative worlds. New Haven, CT: Yale University Press.

Green, M. C. (2004). Transportation into narrative worlds: The role of prior knowledge and perceived realism. Discourse Processes, $38,247-266$.

Green, M. C. \& Brock, T. C. (2000). The role of transportation in the persuasiveness of public narratives. Journal of Personality and Social Psychology, 79, 701-721.

Green, M. C. \& Brock, T. C. (2002). In the mind's eye. Transportation-imagery model of narrative persuasion. In M. C. Green, J. J. Strange, \& T. C. Brock (Eds.), Narrative impact: Social and cognitive foundations (pp. 315-341). Mahwah, NJ: Lawrence Erlbaum.

Green, M. C., Brock, T. C., \& Kaufman, G. F. (2004). Understanding media enjoyment: the role of transportation into narrative worlds. Communication Theory, 14, $\overline{311-327 .}$

Hall, A. E. (2003). Reading realism: audiences' evaluations of the reality of media texts. Journal of Communication, 53(4), 624-641.

Henning, B., and Vorderer, P. (2001). Psychological escapism: Predicting the amount of television viewing by need for cognition. Journal of Communication, 51, 100120.

Johnson-Laird, P. N. (1983). Mental models. Cambridge, England: Cambridge University Press.

Katz, E. \& Foulkes, D. (1962). On the use of the mass media as "escape": Clarification of a concept. Public Opinion Quarterly, 26, 377-388.

Laszlo, J. \& Cupchik, G. C. (1995). The role of affective processes in reading time and time experience during literary reception. Empirical Studies of the Arts, 13, 25-37. 
Lombard, M. \& Ditton, T. (1997). At the heart of it all: The concept of presence. Journal of Computer-Mediated Communication, 13.

Lombard, M., Reich, R. D., Grabe, M. E., Bracken, C. C., \& Ditton, T. B. (2000). Presence and television: the role of screen size. Human Communication Research, 26(1), 75-98.

Nabi, R. L. \& Krcmar, M. (2004). Conceptualizing media enjoyment as attitude: Implications for mass media effects research. Communication Theory, 14(4), 288310.

Nell, V. (1988). Lost in a book. The psychology of reading for pleasure. New Haven: Yale University Press.

Oatley, K. (1994). A taxonomy of literary response and a theory of identification in fictional narrative. Poetics, $23, \overline{53-74 .}$

Oatley, K. (1999). Meetings of minds: Dialogue, sympathy, and identification, in reading fiction. Poetics, 26, 439-454.

Oatley, K. \& Gholamain, M. (1997). Emotions and identification. Connections between readers and fiction. In M. Hjort \& S. Laver (Eds.), Emotion and the arts (pp. 263-298). New York, Oxford: Oxford University Press.

Oatley, K. \& Johnson-Laird, P. N. (1996). The communicative theory of emotions: empirical tests, mental models, and implications for social interaction. In L. L. Martin \& A. Tesser (Eds.), Striving and feeling: interactions among goals, affect, and self-regulation (pp. 363-393). Mahwah, NJ: Erlbaum.

Oliver, M. B. (1993). Exploring the paradox of the enjoyment of sad films. Human Communication Research, 19, 315-342.

Perry, S. D., Jenzowsky, S. A., Hester, J. B., King, C. M., \& Yi, H. (1997). The influence of commercial enjoyment on program enjoyment and evaluation. Journalism and Mass Communication Quarterly, 74, 388-399.

Prince, G. (1982). Narratology. The form and functioning of narrative. Berlin, New York, Amsterdam: Walter de Gruyter.

Rall, J. \& Harris, P. L. (2000). In Cinderella's slippers? Story comprehension from the protagonist's point of view. Developmental Psychology, 36(2), 202-208.

Raney, A. A. (2003). Disposition-based theories of enjoyment. In J. Bryant, D. Roskos-Ewoldsen, \& J. Cantor (Eds.), Communication and emotion: Essays in honor of Dolf Zillmann (pp. 61-84): Lawrence Erlbaum.

Raney, A. A. (2004). Expanding disposition theory: Reconsidering character liking, moral evaluations, and enjoyment. Communication Theory, 14(4), 348-369.

Raney, A. A. \& Bryant, J. (2002). Moral judgment and crime drama: An integrated theory of enjoyment. Journal of Communication, 52, 402-415.

Segal, E. M. (1995a). A cognitive-phenomenological theory of fictional narrative. In J. F. Duchan, G. A. Bruder, \& L. E. Hewitt (Eds.), Deixis in narrative. A cognitive science perspective (pp. 61-78). Hillsdale, NJ: Lawrence Erlbaum Associates.

Segal, E. M. (1995b). Narrative comprehension and the role of Deictic Shift Theory. In J. F. Duchan, G. A. Bruder, \& L. E. Hewitt (Eds.), Deixis in narrative. A cognitive science perspective (pp. 3-17). Hillsdale, NJ: Lawrence Erlbaum Associates.

Sherry, J. L. (2004). Flow and media enjoyment. Communication Theory, 14(4), $328-347$.

Tan, E. S. (1996). Emotion and the structure of narrative film. Film as an emotion machine. Mahwah, New Jersey: Lawrence Erlbaum.

van Dijk, T. A. \& Kintsch, W. (1983). Strategies of discourse comprehension. New York: Academic Press.

Wirth, W., Hartmann, T., Böcking, S., Vorderer, P., Klimmt, C., Schramm, H., et al. (2007). A process model of the formation of spatial presence experiences. Media Psychology, 9, 493-525. 
Wyer, R. S., Jr. (2004). Social comprehension and judgment. The role of situation models, narratives, and implicit theories. Mahwah, NJ: Lawrence Erlbaum.

Zwaan, R. A., Langston, M. C., \& Graesser, A. C. (1995). The construction of situation models in narrative comprehension: An event-indexing model. Psychological Science, 6(5), 292-297.

Zwaan, R. A., Magliano, J. P., \& Graesser, A. C. (1995). Dimensions of situation model construction in narrative comprehension. Journal of Experimental Psychology: Learning, Memory, and Cognition, 21(2), 386-397. 